\title{
Rain rate measurements over global oceans from IRS-P4 MSMR
}

\author{
A K Varma, R M Gairola, Samir Pokhrel, B S Gohil, A K Mathur and \\ VIJAY K AGARWAL \\ Oceanic Sciences Division, Space Applications Centre (ISRO), \\ Ahmedabad 380 015, India \\ e-mail: atul_varma@hotmail.com
}

In this paper rain estimation capability of MSMR is explored. MSMR brightness temperature data of six channels corresponding to three frequencies of 10,18 and $21 \mathrm{GHz}$ are colocated with the TRMM Microwave Imager (TMI) derived rain rates to find a new empirical algorithm for rain rate by multiple regression. Multiple correlation analysis involving various combinations of channels in linear and non-linear forms and rain rate from TMI is carried out, and thus the best possible algorithm for rain rate measurement was identified which involved $\mathrm{V}$ and $\mathrm{H}$ polarized brightness temperature measurements at 10 and $18 \mathrm{GHz}$ channels. This algorithm explained about 82 per cent correlation $(r)$ with rain rate, and $1.61 \mathrm{~mm} \mathrm{~h}^{-1}$ of error of estimation.

Further, this algorithm is used for generating global average rain rate map for two contrasting months of August (2000) and January (2001) of northern and southern hemispheric summers, respectively. MSMR derived monthly averaged rain rates are compared with similar estimates from TRMM Precipitation Radar (PR), and it was found that MSMR derived rain rates match well, quantitatively and qualitatively, with that from PR.

\section{Introduction}

The importance of tropical precipitation to the global climate has been known to the meteorological and oceanographic community for a long time. Many concerted efforts for systematic study of precipitation structures and their role in regional weather have been undertaken. The Tropical Rainfall Measuring Mission (TRMM) initiated jointly by USA and Japan, pioneered the first cocoordinated international effort to study tropical rainfall from satellite measurements. The launch of the Indian Remote Sensing Satellite (IRS-P4) with a multichannel passive microwave radiometer, was attempted for rainfall estimation in the present study. This satellite carried a Multichannel Scanning Microwave Radiometer (MSMR) and an Ocean Colour Monitor (OCM) onboard. MSMR provides measurements of brightness temperatures at $6.6,10,18$ and $21 \mathrm{GHz}$ frequencies in both horizontal and vertical polarisations. The operational geophysical parameters available from MSMR measurements are wind speed, cloud liquid water, water vapour and surface temperatures over the global oceans (Gohil et al 2000). After the satellite was launched, a detailed campaign for validation of MSMR derived geophysical parameters was carried out using both in situ (Ali 2000) and other satellite data (Varma et al 1999a, 2002). All geophysical parameters matched well with in situ and other satellite measurements. The only exception was cloud liquid water.

A major mile stone was achieved in the satellite based rain rate estimation when DMSP-F8 launched in June 1987 carried a Special Sensor Microwave/Imager (SSM/I) (Hollinger 1991) with an additional $85 \mathrm{GHz}$ channel sensitive to the volume scattering by precipitation. More recently

Keywords. IRS-P4, MSMR, TRMM, TMI, PR. 
TRMM satellite was launched with various sensors for precipitation measurement. An advanced version of SSM/I, called TMI (TRMM Microwave Imager) onboard TRMM has shown its worth for global rainfall estimation. TMI is very similar to $\mathrm{SSM} / \mathrm{I}$ except for additional channels at $10.65 \mathrm{GHz}$ $(V \& H)$ which are very sensitive to the raindrops and least sensitive to the cloud liquid and water vapour (Paris 1971).

MSMR frequencies and channels are similar to those of SMMR on board the Nimbus satellite. Sensitivity of the MSMR channels to rain rate is studied using radiative transfer simulations by Gairola et al (2000). Currently, various techniques are used for rainfall retrieval like non-linear regression (e.g., Bauer and Schluessel 1993; Ferraro and Marks 1995; Varma et al 1999b, etc.), Bayesian approach e.g., (Kummerow et al 1996) and neural network approach (e.g., Tsintikidis et al 1997; Gairola et al 2001; Bauer et al 2001, etc.). For the first time TRMM also provided vertical structure of precipitation over land and ocean with a precipitation radar (PR) sensor. In this paper, an attempt is made to find an empirical algorithm for rain rate measurement using MSMR brightness temperatures and concurrent rain rates measurements from TMI. Monthly rain rate measurements from MSMR are compared with similar maps from TRMM-PR, both quantitatively and qualitatively.

\section{Instruments and data}

\subsection{MSMR data}

MSMR covers a swath of about $1350 \mathrm{~km}$ and it achieves a complete global coverage in two days. MSMR brightness temperature data used in this study are provided by National Remote Sensing Agency (NRSA), Hyderabad, India as daily global data files on three different resolution grids of 50 , 75 and $150 \mathrm{~km}$, which are referred to as grid 1, grid 2 and grid 3 respectively. The $150 \mathrm{~km}$ grid data file contains brightness temperature from all 8 channels, whereas the $75 \mathrm{~km}$ grid data file contains brightness temperatures (Tbs) from 6 channels (all channels except $6.6 \mathrm{GHz}$ ) and the $50 \mathrm{~km}$ grid data file contains Tbs from 4 channels (all channels except 6.6 and $10.65 \mathrm{GHz}$ ). Data values in each of the grid points are provided with corresponding time tag, geo-location and quality flag etc. The present study uses grid 2 data that does not contain $6.6 \mathrm{GHz}$ brightness temperature values.

\subsection{TMI data}

Tropical Rainfall Measuring Mission satellite is in a low inclination $\left(35^{\circ}\right)$, low altitude $(\sim 350 \mathrm{~km}$ which has been recently augmented to the new orbital height of $402.5 \mathrm{~km}$ ), and non-sunsynchronous orbit. The satellite carries three primary instruments for rain measurements, viz., a $\mathrm{Ku}$ band Precipitation Radar (PR), a 5 frequencies, 9 channel, TRMM Microwave Imager (TMI), and a 5 frequencies Visible/Infrared Scanner (VIRS). TMI works in 10.65, 19.35, 21, 37 and $85.5 \mathrm{GHz}$. All frequencies are received in $H$ and $V$ polarizations except $21 \mathrm{GHz}$ which is received only in $V$ polarization. The TMI scans conically over a swath of $760 \mathrm{~km}$ with an instantaneous field of view of varying sizes from $6.7 \mathrm{~km}$ for $85.5 \mathrm{GHz}(V)$ to $60.1 \mathrm{~km}$ for $10 \mathrm{GHz}(H)$ in along track direction, and $4.1 \mathrm{~km}$ for $85.5 \mathrm{GHz}$ $(V)$ to $36.4 \mathrm{~km}$ for $10 \mathrm{GHz}(H)$ in across track direction. The Wentz generated TMI finished product data, which are resampled at about $10 \mathrm{~km}$ cell size, are used in this study. These data are obtained from Global Hydrology Resource Center (GHRC), NASA on exabytes. These data contain TMI derived global oceanic measurements of wind speed (with and without use of $10.65 \mathrm{GHz}$ channel), integrated water vapour, cloud liquid water, sea surface temperature and rain rate (with and without use of $10.65 \mathrm{GHz}$ channel). This product is used to find algorithm for rain rate measurement from MSMR brightness temperatures.

\subsection{PR data}

The $\mathrm{PR}$ is the first rain radar in space. Its primary goal is to provide a three-dimensional structure of quantitative rainfall, particularly of the vertical distribution over land as well as over oceans.

In the present study the monthly surface rainfall known as TRMM PR Level-3 standard product is used. The Earth Observation Research Centre, National Space Development Agency of Japan (EORC, NASDA) provided the data set. The data used are called 3A25G2 and are available in highresolution grid $2\left(0.5^{\circ} \times 0.5^{\circ}\right)$ in binary format. The PR algorithm provides the rain intensity at the nearest bin from the surface, which is not influenced by ground clutter in each angle bin.

\section{Data analysis and results}

MSMR measurements are converted into brightness temperature and are provided with a data set. For this study we used MSMR grid-2 $(75 \mathrm{~km})$ data that contained brightness temperatures in 10 , 18 and $21 \mathrm{GHz}$ channels. Data over the oceans are selected, using global topography data, ETOPO5, generated by Defense Mapping Agency (USA). In order to avoid any possible contamination by the land area, MSMR data that is $2^{\circ}$ away from 


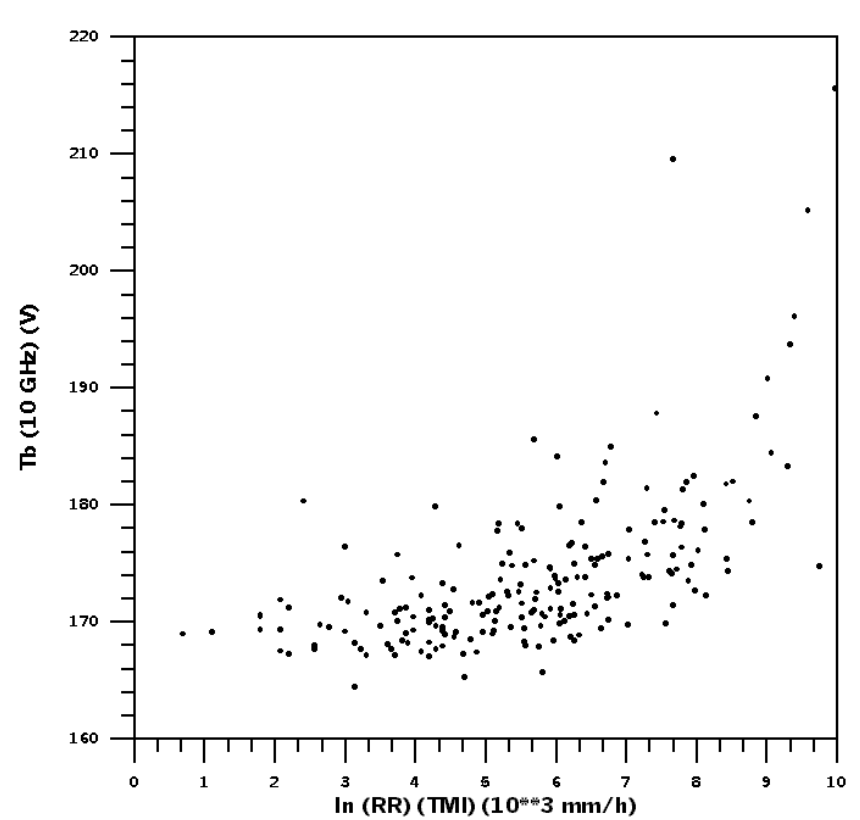

(a)

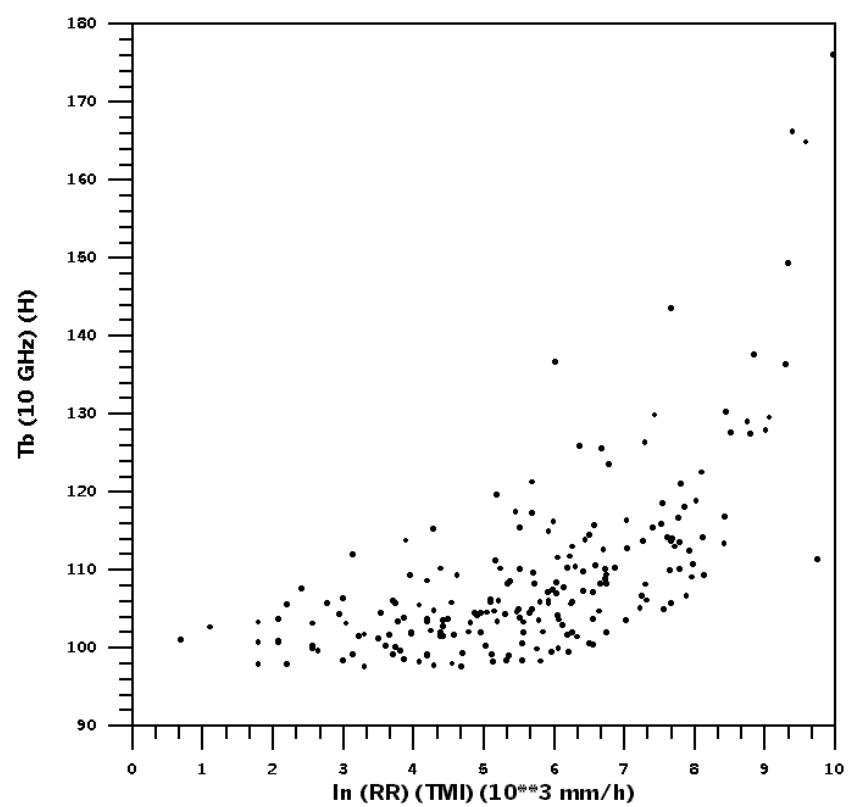

(b)

Figure 1. (a) Rain rate (TMI) versus MSMR $10 \mathrm{GHz}(V)$ brightness temperature, (b) same as $1($ a) but for $10 \mathrm{GHz}(H)$.

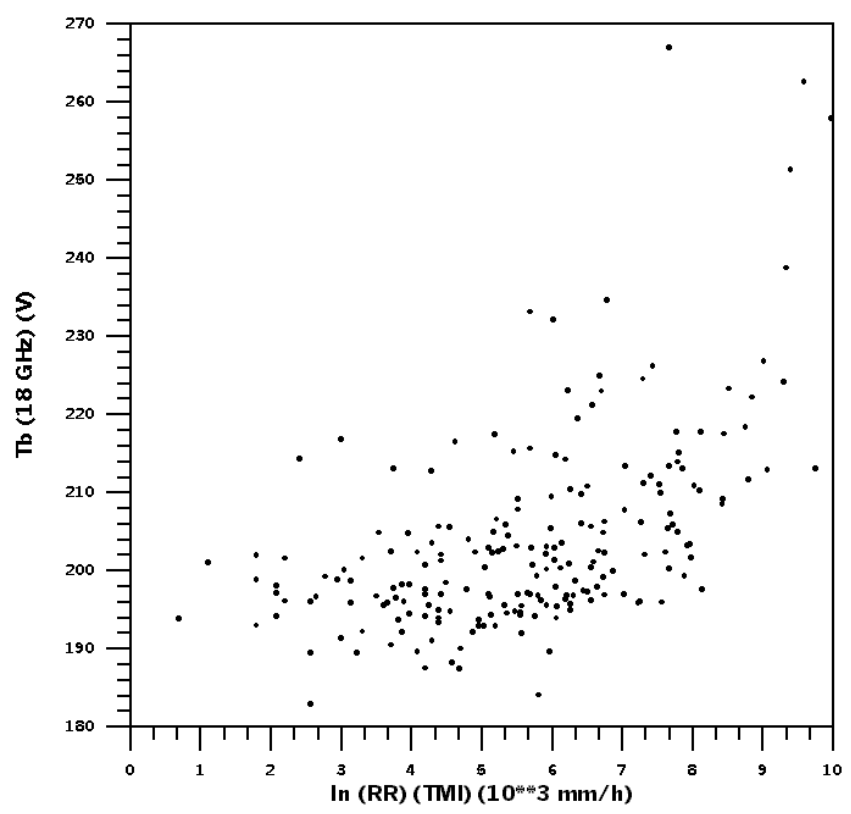

(a)

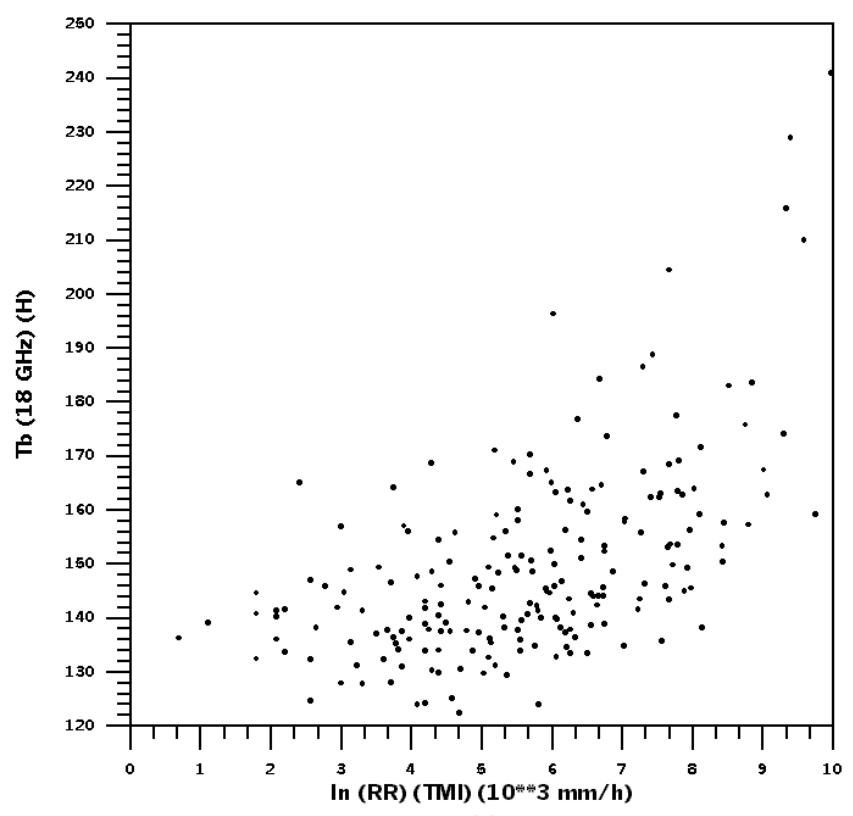

(b)

Figure 2(a and b). Same as figure 1 ( $\mathrm{a}$ and $\mathrm{b})$ but for $18 \mathrm{GHz}$ brightness temperature.

the land only is selected for this study. First, the MSMR brightness temperature data from 14th-23rd July 1999 covering the global oceans are extracted and colocated with near concurrent TMI Wentz finished-product data set. TMI data are available on resampled cell of about $\sim 10 \mathrm{~km}$. Before colocating with MSMR observations, TMI rain rate data are averaged in $8 \times 8$ grid to make it spatially compatible to the size of MSMR grid2. Due to high spatial and temporal variability of rainfall, two data sets are colocated within a spa- tial difference of $0.25^{\circ}$ and temporal difference of 10 minutes, to ensure more than 50 per cent spatial overlap within small time difference (as compared to the life span of a typical convective cell) of two data sets of TMI and MSMR.

Figure 1 ( $a$ and $b$ ) shows the colocated TMI rain rate (RR) and MSMR brightness temperature for $10 \mathrm{GHz}$ (Tb10) channels. In order to improve visibility of the large number of points falling towards low rainfall values, a logarithmic scale for rainfall is used. Good correlations are found 

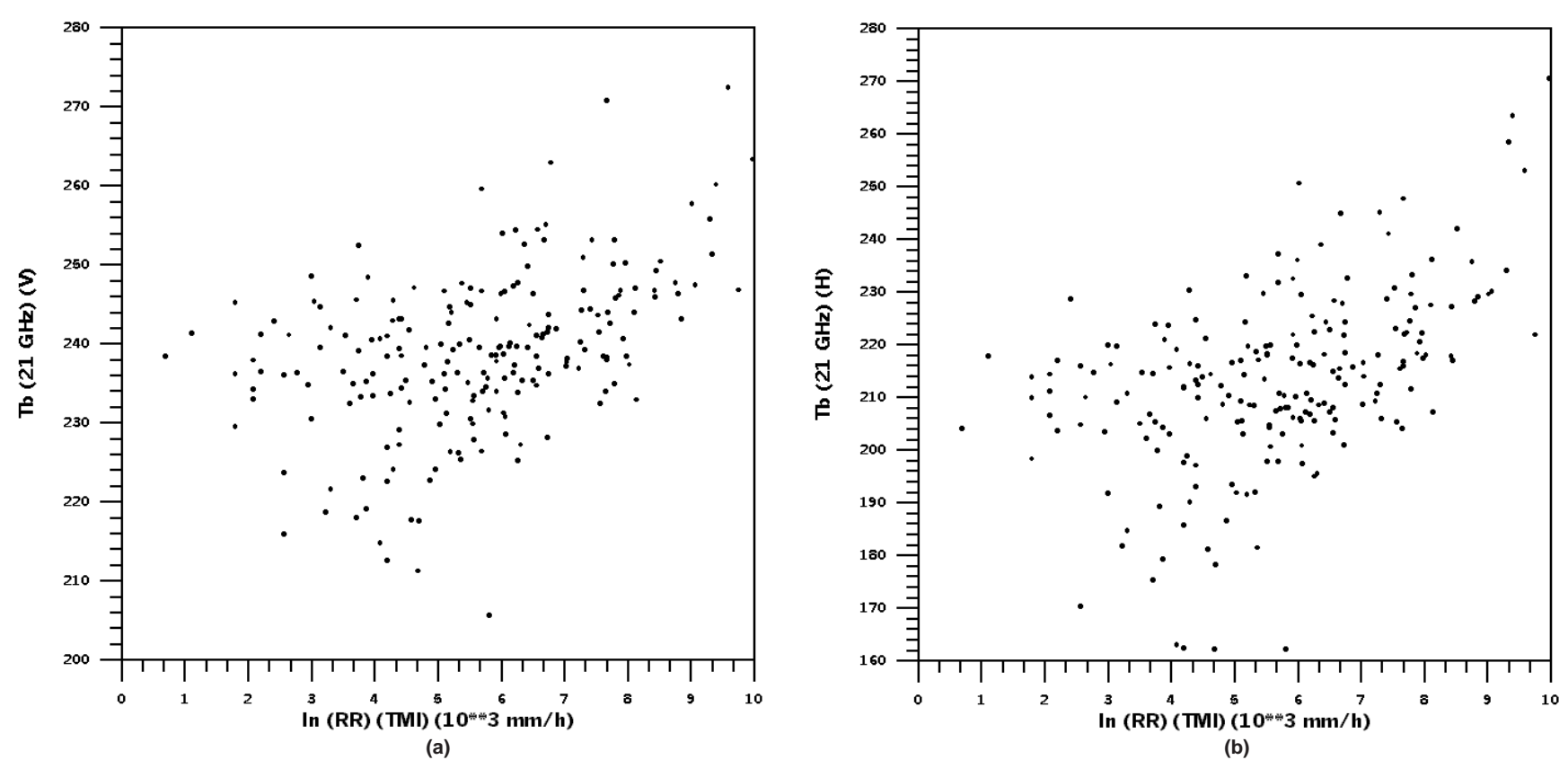

Figure $3(\mathrm{a}$ and $\mathrm{b})$. Same as figure 1 ( $\mathrm{a}$ and $\mathrm{b}$ ) but for $21 \mathrm{GHz}$ brightness temperature.

between TMI RR and MSMR Tb-10 GHz channels. A second order polynomial fit explains correlation for $10 \mathrm{GHz}$ vertically polarized Tbs (Tb10V) about 0.69 and that for horizontally polarized Tbs $(\mathrm{Tb} 10 \mathrm{H})$ about 0.75 . Similarly, figure 2 (a and b) and 3 ( $\mathrm{a}$ and $\mathrm{b}$ ) show relationships between TMI RR and Tbs from 18 and $21 \mathrm{GHz}$ channels, respectively. Like figure 1 , in figure 2 and 3 also the rain rate is plotted on a logarithmic scale. A second order polynomial fit explains correlation between TMI logarithmic RR and MSMR Tbs is significantly high in case of all the 6 channels. For $18 \mathrm{GHz} V(\mathrm{~Tb} 18 \mathrm{~V})$ and $H(\mathrm{~Tb} 18 \mathrm{H})$ correlation with rain rate is about 0.62 and 0.64 , respectively, and that for $21 \mathrm{GHz}, V(\mathrm{~Tb} 21 \mathrm{~V})$ and $H$ $(\mathrm{Tb} 21 \mathrm{H})$ channels is 0.51 and 0.56 , respectively. In order to have large variability over logarithmic scale, the plotted rain rate in all three figures is in $\mu \mathrm{m} / \mathrm{h}$ (i.e., $10^{-3} \mathrm{~mm} / \mathrm{h}$ ) In general, the correlation of RR with $H$ polarized Tbs appears comparatively higher as compared to the $V$ polarized Tbs for all three frequencies, with a fall in the value from $10 \mathrm{GHz}$ to $21 \mathrm{GHz}$ frequency. This is in agreement with the results of Gairola et al (2000) where they presented sensitivity of MSMR channels to rain rate using radiative transfer simulations.

Multiple regressions of $\mathrm{RR}$ and $\mathrm{Tbs}$ were attempted further from different channels of MSMR. Multiple correlation using linear and non-linear forms of the regression equation are attempted. Non-linear form is selected based on the general nature of brightness temperature with RR (Wilheit et al 1991). The linear form is selected as follows:

$$
\begin{aligned}
R R= & a_{0}+a_{1} \mathrm{~Tb} 10 V+a_{2} \mathrm{~Tb} 10 H+a_{3} \mathrm{~Tb} 18 V \\
& +a_{4} \mathrm{~Tb} 18 H+a_{5} \mathrm{~Tb} 21 V+a_{6} \mathrm{~Tb} 21 H
\end{aligned}
$$

The non-linear form selected is as follows:

$$
\begin{aligned}
R R= & a_{0}^{\prime}+a_{1}^{\prime} \ln [280-\mathrm{Tb} 10 V]+a_{2}^{\prime} \ln [280-\mathrm{Tb} 10 H] \\
& +a_{3}^{\prime} \ln [280-\mathrm{Tb} 18 V]+a_{4}^{\prime} \ln [280-\mathrm{Tb} 18 H] \\
& +a_{5}^{\prime} \ln [280-\mathrm{Tb} 21 V]+a_{6}^{\prime} \ln [280-\mathrm{Tb} 21 H]
\end{aligned}
$$

where, Tb10V, Tb10H, Tb18V, Tb18H, Tb21V and $\mathrm{Tb} 21 H$ are brightness temperatures for corresponding channels, $a_{0}, a_{1}, a_{2}, a_{3}, a_{4}, a_{5}, a_{6}$ are regression coefficients for linear fit and $a_{0}^{\prime}, a_{1}^{\prime}, a_{2}^{\prime}, a_{3}^{\prime}, a_{4}^{\prime}, a_{5}^{\prime}, a_{6}^{\prime}$ regression coefficients for nonlinear fit.

In order to develop a most appropriate algorithm, we used different combinations of brightness temperatures in equation (2) and worked out values of multiple correlation $(R)$, error of estimation $(E)$, error in each coefficient $\left(E_{c}\right)$, and F-test. We have chosen algorithm for rainfall estimation from MSMR for which $R, E$ and $E_{r}$ are optimum. In equation form, this algorithm results in the following equation:

$$
\begin{aligned}
R R(\mathrm{~mm} / \mathrm{h})= & 241.1-17.57 \ln [280-\mathrm{Tb} 10 V] \\
& -40.65 \ln [280-\mathrm{Tb} 10 H]+5.478 \ln \\
& {[280-\mathrm{Tb} 18 V]+5.621 \ln [280-\mathrm{Tb} 18 H] }
\end{aligned}
$$

Using this equation, daily global rainfall from MSMR is computed for all the days of August 2000 

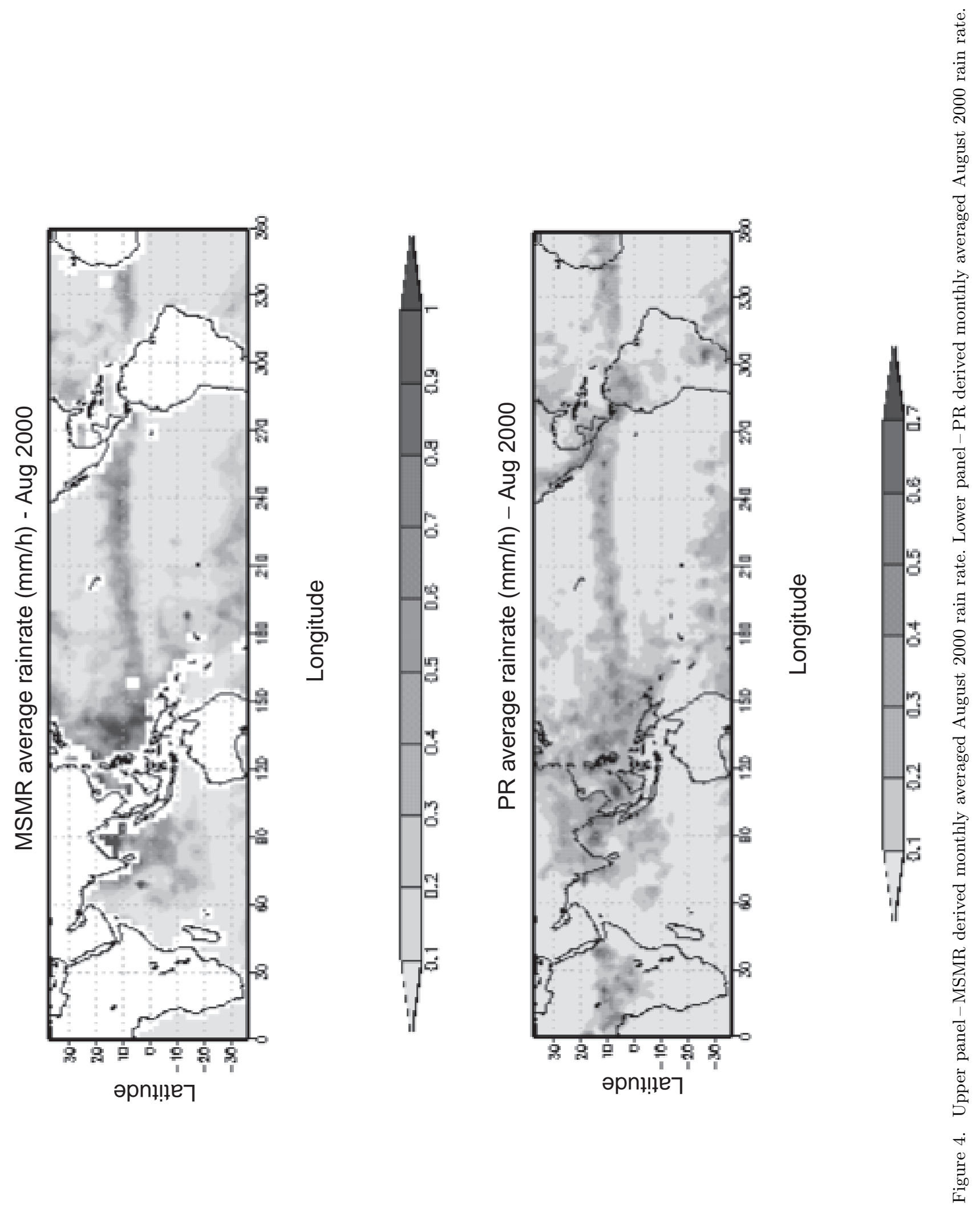

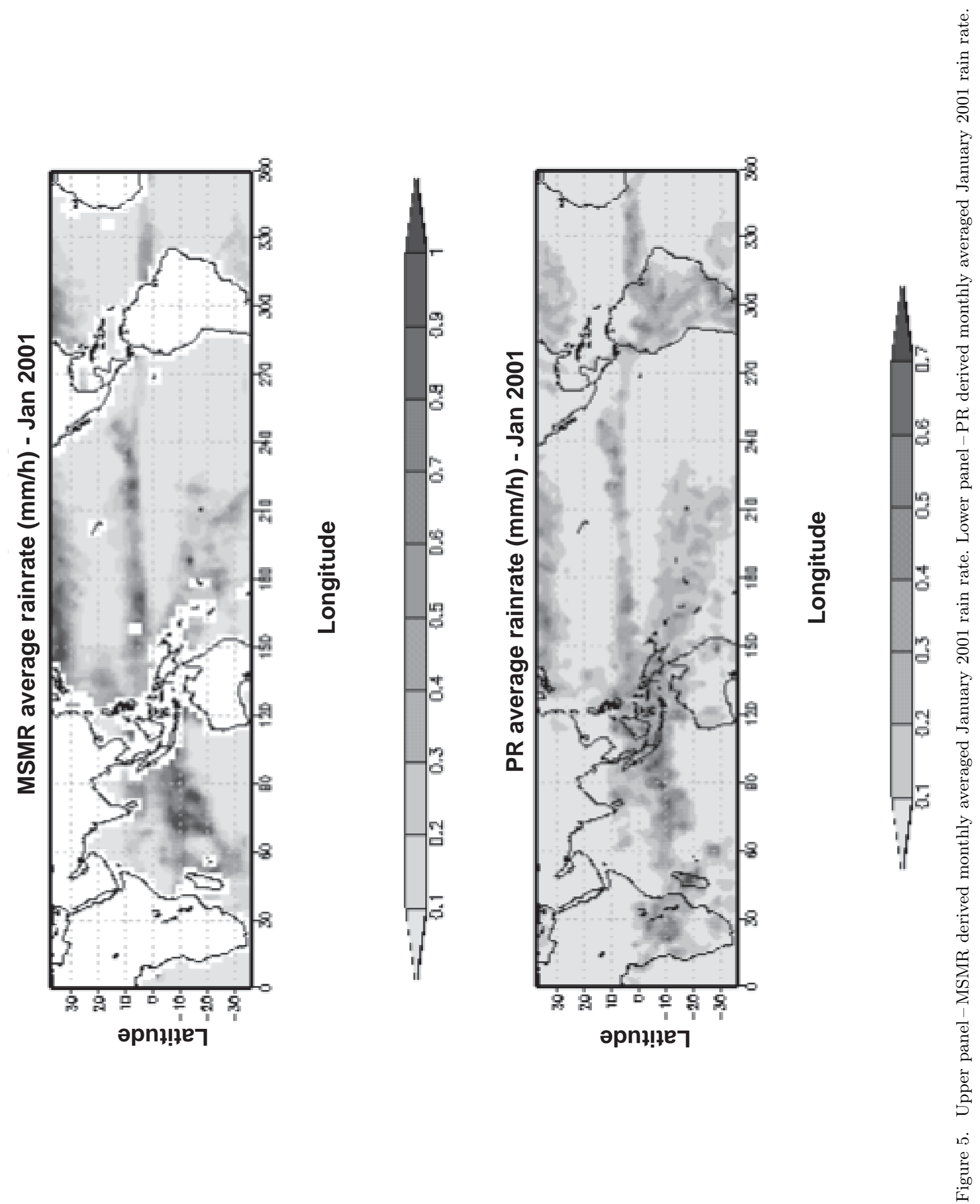

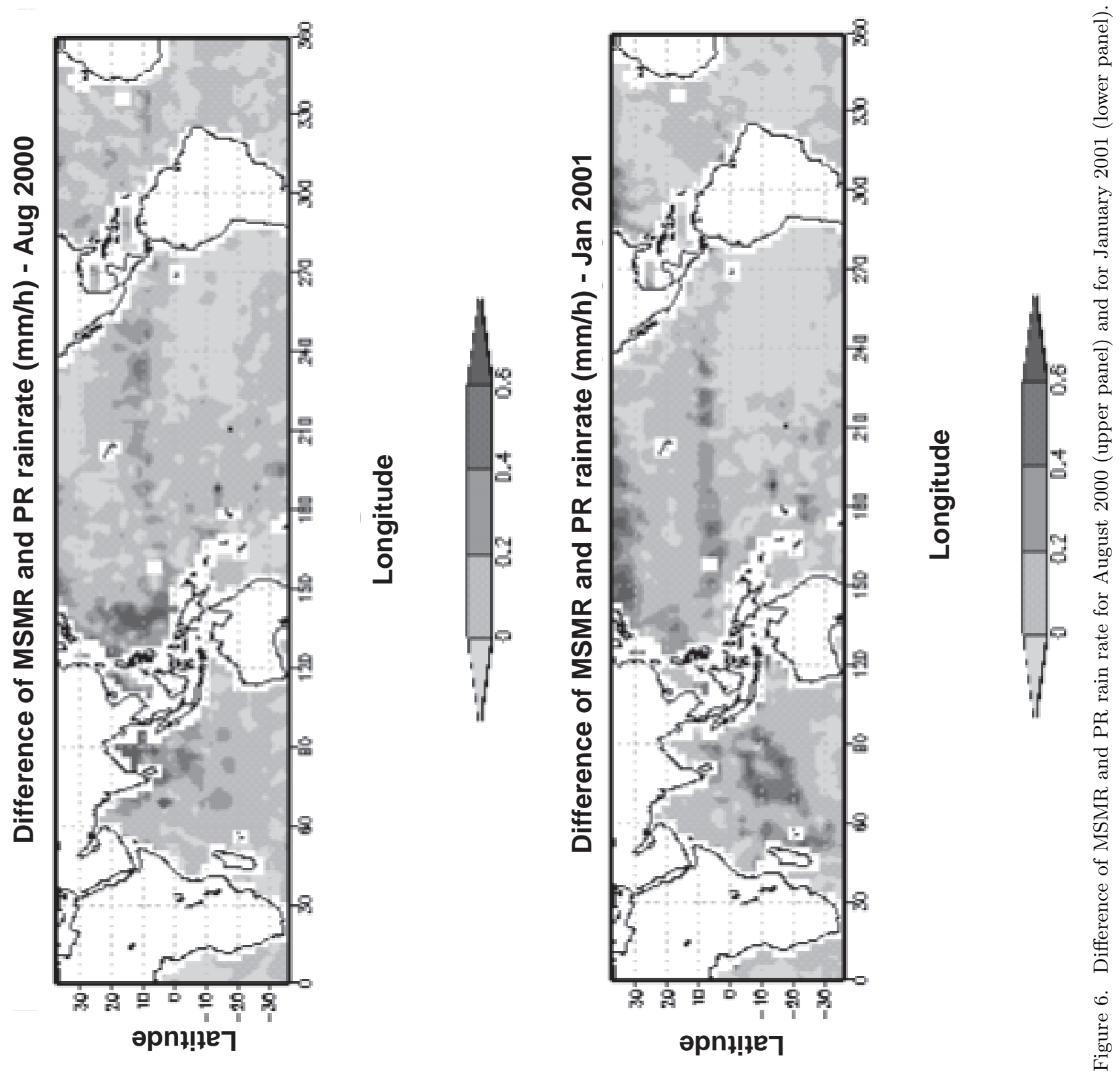

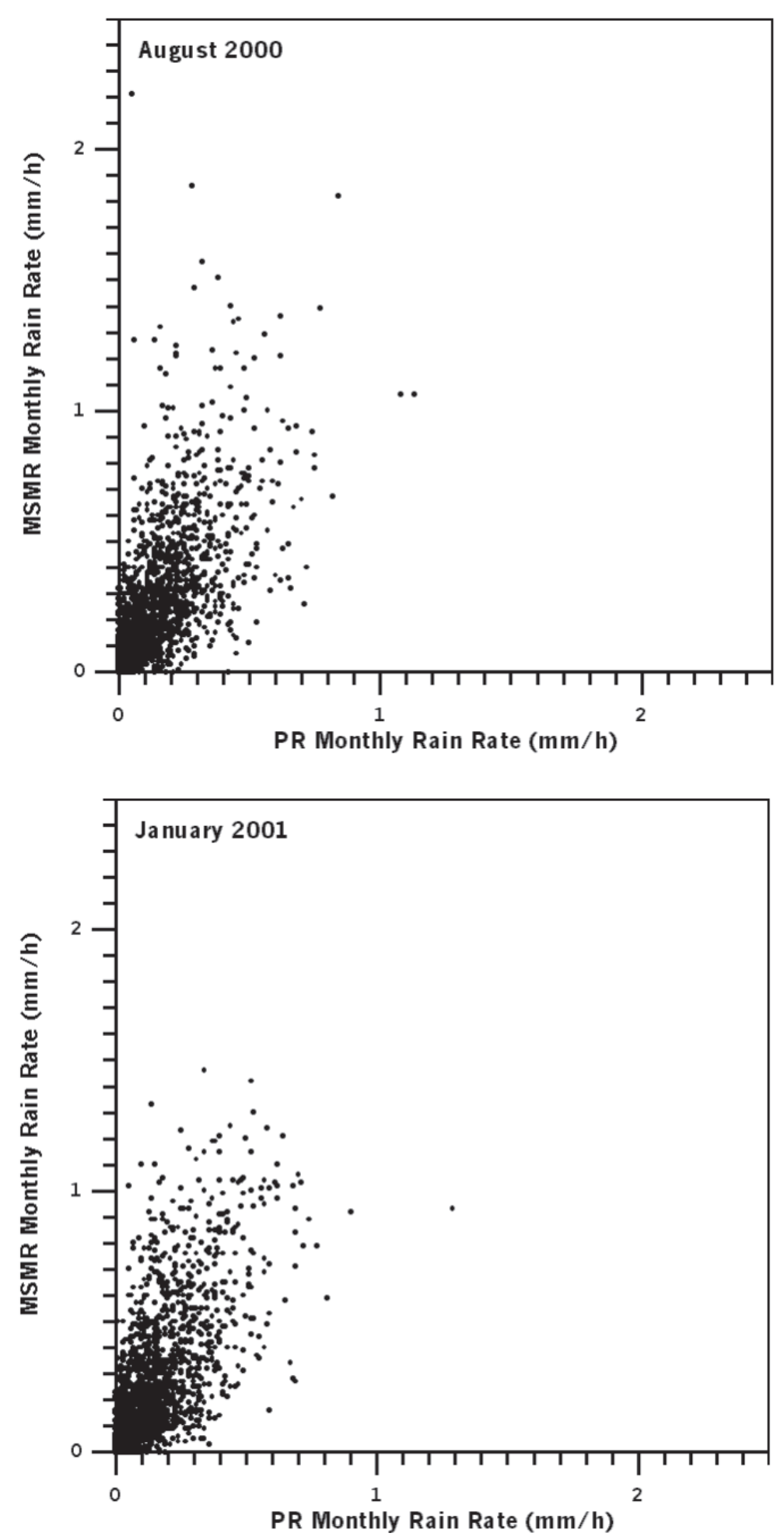

Figure 7. (a) Scatter plot between MSMR and PR monthly rain rate from figure 4. (b) Scatter plot betweem MSMR and PR monthly rain rate from figure 5 .

and January 2001 and then averaged in $2.5^{\circ} \times 2.5^{\circ}$ to produce monthly averaged rain rate maps. The upper panel of figure 4 shows the monthly averaged MSMR rain rate map for August 2000. For comparison, the lower panel shows the $\mathrm{PR}$ rain rate. The data plotted in $\mathrm{PR}$ map are averaged in $2.5^{\circ} \times 2.5^{\circ}$ latitude-longitude grid. The correlation coefficient and rms difference between MSMR and $\mathrm{PR}$ rain-rates is found as 0.71 and $0.18 \mathrm{~mm} \mathrm{~h}^{-1}$ for August 2000 and 0.74 and $0.18 \mathrm{~mm} \mathrm{~h}^{-1}$ for January, 2001, respectively. The difference of MSMR and PR rain rate is plotted in figure 6 (upper 
panel). Similarly, for January 2001, MSMR and $\mathrm{PR}$, rain maps are shown in upper and lower panels of figure 5, and the difference of the two is plotted in figure 6 (lower panel). Figure 7 (a and b), shows the scatter plot of monthly average rain rate from MSMR and PR from figures 4 and 5, respectively.

The MSMR rain rates, as presented in figures 4 and 5 (upper panel) are reasonably well matched, qualitatively, with $\mathrm{PR}$ rain rate. All major rain events are nicely picked up by MSMR. The low rain regions are also well presented by MSMR. Quantitative comparison of monthly average MSMR and PR rain rate (figures 6 and 7 ), suggests that MSMR systematically over estimate the rainfall values. A line of best fit in both (a) and (b) of figure 7 suggests an equal and small intercept of 0.03 , and nearly identical slope of 0.39 and 0.40 , respectively. While comparing the figures, it is important to note that the characteristics of the satellites, sensors, time of observation, and nature of algorithms for measurement of rain rate from two satellites is not the same. MSMR orbit is designed by keeping in view the requirement of the other IRS-P4 onboard sensor Ocean Color Monitor (OCM), and thus they are not appropriate to capture known diurnal variability of tropical rainfall. It crosses over the equator at noon and at midnight. Hence, some discrepancies are obvious. Despite this fact, the general nature of rain events picked up by them, especially along the South Pacific Convergence Zone (SPCZ) and Inter Tropical Convergence Zone (ITCZ) in the Pacific are very well matched. In the Indian Ocean region, the vigor of monsoon is represented well by MSMR. In general, it appears that MSMR has the potential for rainfall measurement over oceans.

\section{Conclusions}

Unlike TMI and SSM/I, which are capable of providing rainfall over the land as well as over sea, MSMR is able to provide rain measurements only over the oceans due to non-availability of high frequency $(85 \mathrm{GHz})$ channels. PR is a state-of-art sensor for rain measurement. The MSMR derived monthly rain values are in good comparison with similar values from PR. Some discrepancies in the two rain maps are possible because of a variety of reasons as stated earlier. In the light of the results of the WetNet PIP-2 project, where large discrepancies are reported among various SSM/I algorithms (Smith et al 1998), the comparison of monthly averaged PR and MSMR derived rain rates is very encouraging.

\section{Acknowledgement}

Authors are thankful to GHRC/NASA for providing TMI data and EORC/NASDA for providing TRMM-PR Level 3 data. Authors are also thankful to Group Director, MOG, and Director, SAC for their encouragement.

\section{References}

Ali M M 2000 Validation of Multifrequency Scanning Microwave Radiometer geophysical parameter data products; Proc. of Pacific Ocean Remote Sensing Conference - 2000, 5-8 December 2000, NIO, Goa, India, pp. 182-191

Bauer P, Ameyank P and Kummerow C D, Smith E A 2001 Over ocean rainfall retrieval from multi sensor data of Tropical Rainfall Measuring Mission (TRMM): Part II Algorithm implementation; J. Atmos. Ocean Tech. 18, Nov. 1838-1855

Bauer P and Schluessel P 1993 Rainfall, total water, ice water, and water vapor over sea from polarized microwave simulations and special sensor microwave/imager data; $J$. Geophys. Res. $\mathbf{9 8}$ pp. 20,737

Ferraro R R and Marks G F 1995 The development of SSM/I rain-rate retrieval algorithms using ground-based radar measurements; J. Atmos. Oceanici Technol. 12 pp. 755

Gairola R M, Mallet C, Viltard N and Moreau E 2001 Rainfall from TRMM-TMI; $2^{\text {nd }} I S R O-C N E S$ Science Workshop on MEGHA-TROPIQUES, 1-5 July, 2001, Paris, France.

Gairola R M, Varma A K, Gohil B S and Agarwal V K 2000 Assessment of TRMM-TMI, DMSP-SSM/I and IRS-P4MSMR observations over the Indian oceanic region, Proc. of Pacific Ocean Remote Sensing Conference - 2000, 5-8 December 2000, NIO, Goa, India, pp. 217-220

Gohil B S, Mathur A K and Varma A K 2000 Geophysical parameter retrieval over global oceans from IRS-P4/MSMR; Proc. of Pacific Ocean Remote Sensing Conference-2000, 5-8 December 2000, NIO, Goa, India pp 207-211

Hollinger J P 1991 DMSP special sensor microwave imager calibration and validation; Naval Research Laboratory, (Washington D.C.) 20375-5000

Kummerow C, Olson W S and Gigleo L 1996 A simplified scheme for obtaining precipitation and vertical hydrometer profiles from passive microwave sensors; IEEE Trans. Geosci. Remote Sens. 34 pp. $1213-1232$

Paris J F 1971 Transfer of thermal microwaves in the atmosphere; vol 1, published by Department of Meteorology, Texas A \& M University, Texas 77843, pp 212

Smith E A, Lamm J E, Adler R, Alishouse K, Aonashi E, Barrett E, Bauer P, Berg W, Chang A, Ferraro R, Ferriday J, Goodman S, Grody N, Kidd C, Kniveton D, Kummerow C, Liu G, Marzano F, Mugnai A, Olson W, Petty G, Shibata A, Spancer R, Wentz F, Wilheit T and Zipser E 1998 Results of WetNet PIP2 project; Journal of Atmospheric Sciences, 55 (9), pp. $1483-1536$

Tsintikidis D, Haferman L, Anagnostou E N, Krazewski W F and Smith T F 1997 A neural network approach to estimating rainfall from spaceborne microwave data; IEEE Trans. Geosci. Remote Sens., 35 5, pp. 1079-1093

Varma A K, Gairola R M, Mathur A K, Gohil B S and Agarwal V K 2002 Intercomparison of IRS-P4-MSMR 
derived geophysical products with DMSP-SSM/I and TRMM-TMI finished products; Proceedings of Indian Academy of Sciences (Earth and Planetary Sciences) (this issue)

Varma A K, Gairola R M, Kishtawal C M, Pandey P C, and Singh K P 1999b Rain rate estimation from nadir looking TOPEX/Poseidon Microwave Radiometer (TMR) for correction of Radar Altimetric measurements; IEEE Transactions on Geosciences and Remote Sensing, 37 (5), pp. 2556-2568
Varma A K, Gairola R M and Gohil B S Comparison of IRS-P4 MSMR and DMSP-SSM/I Geophysical products 1999a Internal Report No.: ISRO/SAC/RESA/MOG/OSD/MSMR/TN/DEC 9903, pp 47.

Wilheit T T, Chang A T C and Chiu L S 1991 Retrieval of monthly rainfall indices from microwave radiometric measurements using probability distribution functions; J. Atmos. and Oceanic. Tech. 8, pp. $118-136$ 